\title{
High Irritation and Removal Rates After Plate or Nail Fixation in Patients With Displaced Midshaft Clavicle Fractures
}

\author{
Martijn H. J. Hulsmans MD, Mark van Heijl MD, PhD, R. Marijn Houwert MD, PhD, \\ Eric R. Hammacher MD, PhD, Sven A. G. Meylaerts MD, PhD, Michiel H. J. Verhofstad PhD, \\ Marcel G. W. Dijkgraaf MD, PhD, Egbert J. M. M. Verleisdonk
}

Received: 14 June 2016/ Accepted: 28 September 2016/Published online: 9 November 2016

(C) The Association of Bone and Joint Surgeons \& 2016

\begin{abstract}
Background Studies comparing plate with intramedullary nail fixation of displaced midshaft clavicle fractures show faster recovery in the plate group and implant-related complications in both groups after short-term followup (6 or 12 months). Knowledge of disability, complications, and removal rates beyond the first postoperative year will help surgeons in making a decision regarding optimal implant choice. However, comparative studies with followup beyond the first year or two are scarce.

Questions/purposes We asked: (1) Does plate fixation or intramedullary nail fixation for displaced midshaft clavicle fractures result in less disability? (2) Which type of fixation, plate or intramedullary, is more frequently associated with implant-related irritation and implant removal? (3) Is plate or intramedullary fixation associated with postoperative complications beyond the first postoperative year?
\end{abstract}

The institution of one or more of the authors (FJW, RMH, EJV) has received, during the study period, funding from the AO Foundation ((Dübendorf, Switzerland).

All ICMJE Conflict of Interest Forms for authors and Clinical Orthopaedics and Related Research ${ }^{\circledR}$ editors and board members are on file with the publication and can be viewed on request.

Each author certifies that his institution approved the human protocol for this investigation, that all investigations were conducted in conformity with ethical principles of research, and that informed consent for participation in the study was obtained.

This work was performed at the Diakonessenhuis Utrecht, Utrecht, The Netherlands; Academic Medical Center, Amsterdam, The Netherlands; St Elisabeth Hospital, Tilburg, The Netherlands; Haaglanden Medical Center, The Hague, The Netherlands; and the St Antonius Hospital, Nieuwegein, The Netherlands.

M. H. J. Hulsmans, M. van Heijl, E. J. M. M. Verleisdonk ( $\square)$ Department of Surgery, Diakonessenhuis Utrecht, PO Box 80250, 3508 TG Utrecht, The Netherlands

e-mail: ejverleisdonk@gmail.com
Methods Between January 2011 and August 2012, patients with displaced midshaft clavicle fractures were enrolled and randomized to plate or intramedullary nail fixation. A total of 58 patients with plate and 62 patients with intramedullary nails initially were enrolled. Minimum followup was 30 months (mean, 39 months; range, 30-51 months). Two patients (3\%) with plate fixation and two patients (3\%) with intramedullary nails were lost to followup. The QuickDASH was obtained at final followup and compared between patients who had plate fixation and those who had intramedullary nail fixation. Postoperative complications measured include infection, implant-related irritation, implant failure, nonunion, and refracture after implant removal. Indications for implant removal included implant-related irritation, implant failure, nonunion, patient's wish, or surgeon's preference.

Results Between patients with plate versus intramedullary nail fixation, there were no differences in QuickDASH

R. M. Houwert

Utrecht Traumacenter, Utrecht, The Netherlands

E. R. Hammacher

Department of Surgery, St Antonius Hospital, Nieuwegein, The Netherlands

S. A. G. Meylaerts

Department of Surgery, Medical Center Haaglanden, The Hague, The Netherlands

M. H. J. Verhofstad

Trauma Research Unit Department of Surgery, Erasmus Medical Centre, University Medical Center Rotterdam, Rotterdam, The Netherlands

M. G. W. Dijkgraaf

Clinical Research Unit, Academic Medical Center Amsterdam, Amsterdam, The Netherlands 
scores (plate, $1.8 \pm 3.6$; intramedullary nail, $1.8 \pm 7.2$; mean difference, $-0.7 ; 95 \% \mathrm{CI},-2.2$ to $2.04 ; \mathrm{p}=0.95)$. The proportion of patients having implant-related irritation was not different (39 of 56 [70\%] versus 41 of 62 [66\%]; relative risk, $1.05 ; 95 \% \mathrm{CI}, 0.82-1.35 ; \mathrm{p}=0.683)$. Intramedullary fixation was associated with a higher likelihood of implant removal (51 of 62 [82\%] versus 28 of 56 [50\%]; relative risk, 1.65 ; 95\% CI, 1.24-2.19; $\mathrm{p}<0.001)$. Among the removed implants more plates than intramedullary nails were removed after the 1-year followup (12 of 28 [43\%] versus six of 51 [12\%]; $\mathrm{p}=0.002)$. There were no infections, implant breakage, nonunions, or refractures between the 1-year and final followup in either group.

Conclusions After a mean followup of 39 months, disability scores were excellent. Major complications did not occur after the 1-year followup. A frequent and bothersome problem after both surgical treatments is implant-related irritation, resulting in high rates of implant removal, after 1 year. Future research could focus on analyzing risk factors for implant irritation or removal.

Level of Evidence Level II, therapeutic study.

\section{Introduction}

During the last few decades, several studies investigating the optimal treatment of displaced midshaft clavicle fractures have been conducted. Sequelae rates up to $46 \%$ after nonoperative treatment were reported and advantages of surgical fixation over nonoperative treatment of these fractures include quicker rehabilitation or return to daily activities and lower nonunion rates $[4,15,20]$. Therefore operative treatment, especially in the young patient who relies on the upper limb for work or sports, has been advised [7]. The two most commonly used techniques for operative treatment of displaced midshaft clavicle fractures are plate fixation and intramedullary (IM) nail fixation.

Studies comparing these techniques showed excellent outcomes in bone healing, functionality, and low rates of major complications requiring revision surgery up to 1 year postoperatively [1, 23]. One frequent and bothersome problem for patients after surgical treatment of displaced midshaft clavicle fractures is implant-related irritation. Reported irritation rates range from $9 \%$ to $44 \%$ after plate fixation and $9 \%$ to $62 \%$ after IM nailing. It often is treated by surgical implant removal (a second operation) [1, 4, 6, 20-23]. However, comparative studies or studies regarding the development of implant-related irritation with followup beyond the first year or two are scarce $[1,4,14,19,23]$.

van der Meijden et al. [21] previously conducted a multicenter randomized controlled trial comparing these operative techniques and confirmed the aforementioned low disability scores, low major complication rates, implant-related irritation, and that implant removal occurs frequently after 6 or 12 months. However, that study did not focus on implant-related irritation, the severity of the subjective implant-related irritation was not classified, and patients were followed only until a maximum of 12 months. We extended the followup because we expected these implants to still cause irritation and to be removed after the 1-year followup. This also might influence the disability scores.

Therefore, the current study provides additional followup on the same patients reported in the previous study [21]. We asked: (1) Does plate fixation or IM nail fixation for displaced midshaft clavicle fractures result in less disability? (2) Which type of fixation, plate or intramedullary, is associated with implant-related irritation and implant removal? (3) Is plate or IM fixation associated with postoperative complications beyond the first postoperative year?

\section{Patients and Methods}

We prospectively investigated the population of a previously published multicenter randomized controlled trial [21]. The original trial compared plate fixation $(n=58$ patients) with IM nail fixation ( $n=62$ patients) for displaced midshaft clavicle fractures and included patients from January 2011 until August 2012. Surgeons participating in this study had extensive experience $(>20$ procedures) with each surgical technique. Outcomes were the DASH and Constant-Murley scores and complications at 2, 6, 12, 24, and 52 weeks [21].

For the current study, patients were contacted between January and March 2015, resulting in a minimum followup of 30 months (mean, 39 months; range, 30-51 months). An independent researcher (RL) performed the followup and conducted all outcome parameters with a telephone survey. Medical files were double-checked for any complications that the patient may not have mentioned.

Patient inclusion, randomization, surgical technique, and postoperative management were explained in detail in the previous study [21].

Data were analyzed according to the intention-to-treat principle. Fifty-eight patients were randomized to plate fixation (27 [47\%] simple fractures and 31 [53\%] wedge or complex fractures) and 62 to IM nailing (24 [39\%] simple fractures and 38 [61\%] wedge or complex fractures). The mean age of the patients in the plate fixation group was 38 years (SD, 14.6 years) and $53(91 \%)$ men participated. The mean age of patients in the IM nailing group was 40 years (SD, 13.2 years) and $60(97 \%)$ men participated. The endpoints for this study were disability (QuickDASH), 
Fig. 1 A schematic representation of the questions regarding implant-related irritation and removal is shown. Patients who had other causes of irritation such as infection or nonunion should be disregarded.

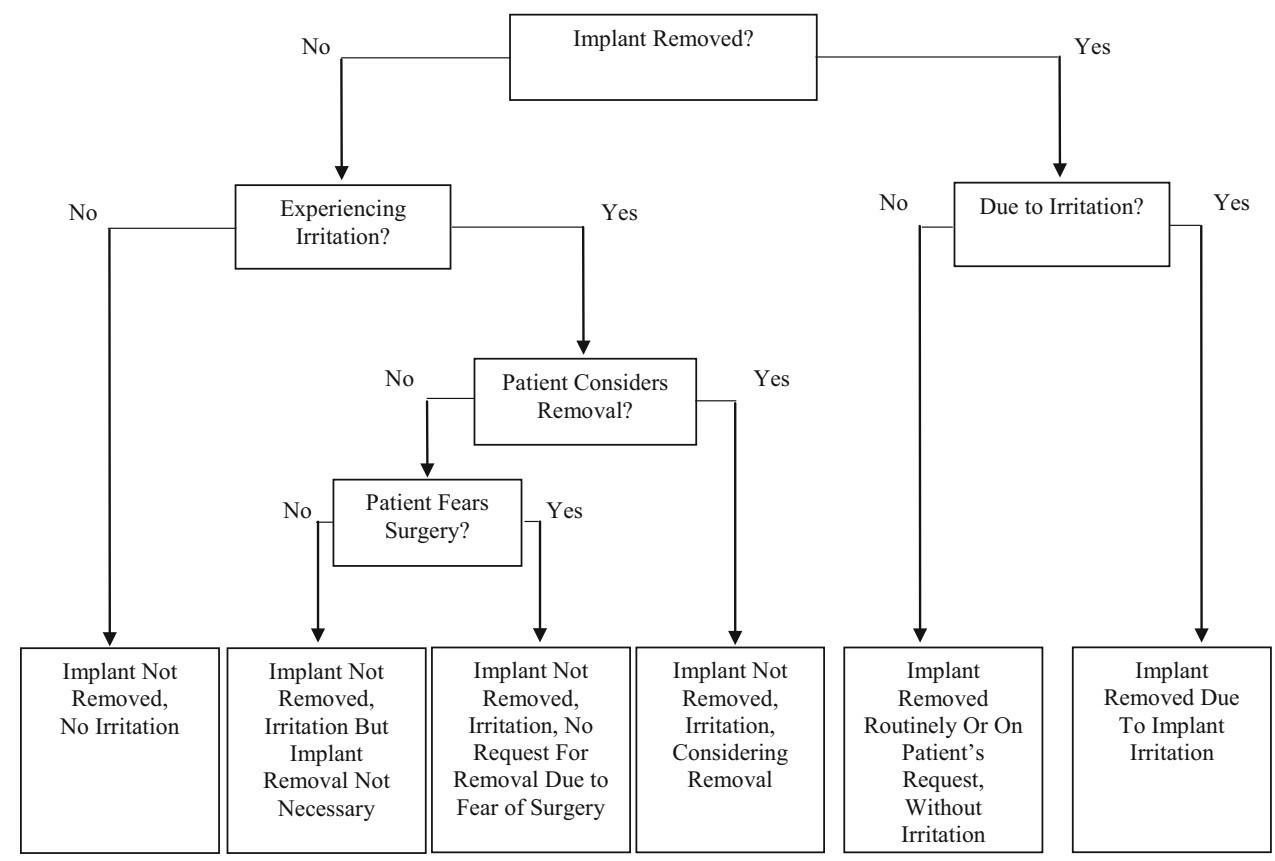

varying degrees of implant-related irritation and implant removal for any reason, and complications that occurred beyond the first postoperative year.

One hundred sixteen patients $(97 \%)$ were contacted in 2015 and four patients (3\%) were lost to followup. Two patients in the plate group were already lost to followup 1 year after surgery. The other two, both in the IM nailing group, had died from cancer. Because they had no complications and their implants had been removed on request before their 1-year followup, data regarding implant-related complications were included for analysis. The mean followup was 39 months (range, 30-51 months).

\section{Outcome Measures}

\section{Disability}

The first section of the survey included the QuickDASH questionnaire, which is a short, validated, reliable patientoriented outcome measure for assessing upper extremity disability. Higher scores represent greater disability and lower scores indicate a better functioning extremity (range, 100-0) [3, 9].

\section{Implant-related Irritation}

The second section of the survey addressed patient-reported implant-related problems, implant removal, and whether surgical consideration was attributable to implant- related irritation. Patients who had other causes of irritation such as infection or nonunion were excluded from this analysis. Patients were asked a series of binary (yes or no) questions that focused on the subsequent actions after these implant-related problems (eg, implant removal). They were asked if the implant was removed, if so, was it attributable to implant-related irritation; and if not, did they experience any kind of implant-related irritation and were they considering removal or was surgery not performed because of fears. The questions were based on extensive clinical experience and designed for easy use in outpatient clinical settings. A schematic representation of the questions is shown in the flowchart (Fig. 1).

\section{Complications}

The last section of the survey addressed complications, interventions needed to treat these complications, and implant removal for the period between 1-year and the final followup.

The same definitions for complications and revisions were used as in the original trial [21]. Minor complications included infection (superficial or deep) and implant-related irritation. Complications requiring revision surgery were considered major and included implant failure, nonunion, and refracture after implant removal. A painful or unpleasant sensation in the affected clavicle in cold environments was considered cold intolerance. In both groups indications for implant removal included implant-related irritation, implant failure, nonunion, patient's wish, or surgeon's preference to prevent future complications. 


\section{Statistical Analysis}

Postoperative outcome scores are presented as mean \pm SD and were compared using Student's t-test for continuous variables (QuickDASH score). Categorical data are presented as absolute numbers (percentage) and were compared using Pearson's chi square test or the Fisher's exact test in case of low cell frequencies. To compare the QuickDASH score in 2015 with the DASH scores obtained during previous followups, the 11 QuickDASH questions were derived from the total DASH scores.

SPSS software (Version 20.0; IBM, Armonk, NY, USA) was used for data analysis. Significance was established at a $\mathrm{p}$ value less than 0.05 .

\section{Results}

Disability

At final followup at 39 months, there were no differences in QuickDASH scores (plate, $1.8 \pm 3.6$; IM nail, $1.8 \pm 7.2$; mean difference, $-0.7 ; 95 \% \mathrm{CI},-2.2$ to $2.04 ; \mathrm{p}=0.945$ ) (Table 1). At earlier times of 1.5, 6, and 12 months, disability scores were not significantly different (Fig. 2). Three months postoperatively there was a significant difference in disability scores in favor of the plate fixation group (plate, $5.1 \pm 7.2$; IM nail, $9.4 \pm 11.6$; mean difference, $-4.3 ; 95 \% \mathrm{CI},-7.9$ to $-0.6 ; \mathrm{p}=0.023$ ).

\section{Implant-related Irritation}

Although the proportion of patients having implant-related irritation was not different (plate, 39 of 56 [70\%]; IM nail, 41 of 62 [66\%]; relative risk, $1.05 ; 95 \%$ CI, 0.8-1.4; p = $0.683)$, IM fixation was associated with a higher likelihood of implant removal (51 of 62 [82\%] versus 28 of 56 [50\%]; relative risk, $1.65 ; 95 \% \mathrm{CI}, 1.2-2.2 ; \mathrm{p}<0.001$ ) (Table 2). The reasons for implant removal did not differ between the plate and the IM groups $(\mathrm{p}=0.551)$. All 28 plates were removed with the patients receiving general anesthesia; 13 IM nails were removed with the patients receiving local anesthesia and 38 were removed with the patients receiving general anesthesia.

A subanalysis of gender-specific implant removal rates showed no difference (male, 74 of 111 [67\%] versus female, five of seven [71\%]; relative risk, 0.93 ; $95 \% \mathrm{CI}$, $0.6-1.5 ; \mathrm{p}=1.000)$.

\section{Complications}

There were no infections, implant failures, nonunions, or refractures between the 1-year and the final followup in either group. Beyond the first postoperative year plate fixation was associated with more implant-related irritation compared with intramedullary fixation (28 of 56 [50\%] versus eight of 60 [13\%]; relative risk, 3.9; 95\% CI, 1.97.8; $\mathrm{p}<0.00$ ) (Table 3). Among the removed implants more plates than IM nails were removed after the 1 year followup (12 of 28 [43\%] versus six of 51 [12\%]; $\mathrm{p}=$ 0.002). Cold intolerance was not different between

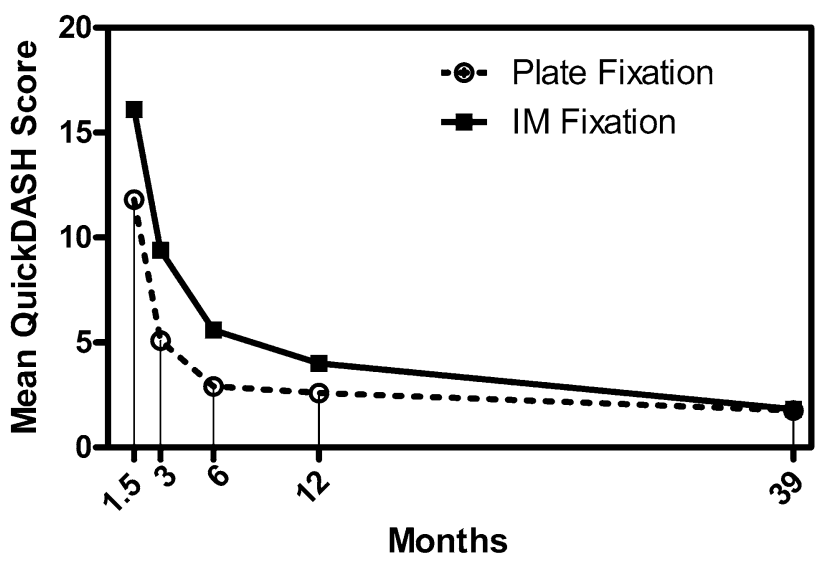

Fig. 2 The graph shows a comparison of the postoperative QuickDASH scores at 11/2, 3, 6, 12 and 39 months.

Table 1. QuickDASH scores after plate or IM nail fixation of displaced midshaft clavicle fractures

\begin{tabular}{lcclc}
\hline Followup & $\begin{array}{l}\text { Plate fixation } \\
(\mathrm{n}=56)^{\dagger}(\mathrm{mean} / \mathrm{SD})\end{array}$ & $\begin{array}{l}\text { Intramedullary fixation } \\
(\mathrm{n}=62)^{*}(\text { mean/SD) }\end{array}$ & Mean difference $(95 \% \mathrm{CI})$ & $\mathrm{p}$ Value \\
\hline 1.5 months & $11.8(12.1)$ & $16.1(14.0)$ & $-4.3(-9.2$ to 0.5$)$ & $-4.3(-7.9$ to 0.6$)$ \\
3 months & $5.1(7.2)$ & $9.4(11.6)$ & $-2.7(-5.8$ to 0.4$)$ & 0.080 \\
6 months & $2.9(5.1)$ & $5.6(9.9)$ & $-1.4(-4.4$ to 1.6$)$ & 0.023 \\
12 months & $2.6(5.2)$ & $4.0(9.8)$ & $-0.7(-2.2$ to 2.0$)$ & 0.347 \\
39 months & $1.8(3.6)$ & $1.8(7.2)$ & 0.945 \\
\hline
\end{tabular}

$\mathrm{IM}=$ intramedullary; ${ }^{\dagger}$ two patients lost to followup; ${ }^{\star} 2$ patients died but were included because their implants had been removed on their request before the 1 year followup. 
Table 2. Classification of implant-related problems based on results of questionnaire (followup = 39 months)

\begin{tabular}{|c|c|c|c|c|}
\hline Classification & $\begin{array}{l}\text { Plate fixation } \\
(\mathrm{n}=56)^{\dagger} \text { Number }(\%)^{*}\end{array}$ & $\begin{array}{l}\text { Intramedullary fixation } \\
(\mathrm{n}=62)^{*} \text { Number }(\%)^{*}\end{array}$ & $\begin{array}{l}\text { Relative risk } \\
(95 \% \mathrm{CI})\end{array}$ & $\mathrm{p}$ Value \\
\hline Implant related irritation & $39(70)$ & $41(66)$ & $1.05(0.8-1.4)$ & 0.683 \\
\hline Implant removed & $28(50)$ & $51(82)$ & $0.61(0.5-0.8)$ & $<0.001 * *$ \\
\hline Reason removed & & & & 0.551 \\
\hline $\begin{array}{l}\text { Attributable to implant-related } \\
\text { irritation }\end{array}$ & $21(75)$ & $35(69)$ & $1.09(0.8-1.5)$ & \\
\hline $\begin{array}{l}\text { Patient's wish or surgeon's } \\
\text { preference }\end{array}$ & $7(25)$ & $16(31)$ & $0.80(0.4-1.7)$ & \\
\hline Status not removed & & & & 0.939 \\
\hline No irritation & $10(36)$ & $5(45)$ & $0.79(0.4-1.8)$ & \\
\hline $\begin{array}{l}\text { Experiencing irritation, but } \\
\text { implant removal not necessary }\end{array}$ & $8(29)$ & $3(27)$ & $1.05(0.3-3.2)$ & \\
\hline $\begin{array}{l}\text { Experiencing irritation, but no } \\
\text { request for removal owing to } \\
\text { fear of reoperation }\end{array}$ & $4(14)$ & $1(9)$ & $1.5(0.2-12.5)$ & \\
\hline $\begin{array}{l}\text { Experiencing irritation, } \\
\text { considering removal }\end{array}$ & $6(21)$ & $2(18)$ & $1.2(0.3-5.0)$ & \\
\hline
\end{tabular}

treatment groups (plate, 10 of 56 [18\%]; IM nail, 10 of 60 [17\%]; relative risk, $1.07 ; 95 \% \mathrm{CI}, 0.5-2.4 ; \mathrm{p}=0.865)$.

\section{Discussion}

In studies comparing plate fixation with IM nail fixation for displaced midshaft clavicle fractures, the majority of complications after 1 year are implant-related [1, 23]. van der Meijden et al. [21] previously reported on this group of patients, and found that until 6 months the plate group experienced less disability than the IM nail group. They also reported low rates of major complications requiring revision surgery, although implant-related irritation occurred frequently within 1 year and often could be treated with implant removal [21]. However, that study did not focus on the implant-related irritation, the severity of the subjective implant-related irritation was not classified, and patients were followed only until a maximum of 12 months. Therefore, we compared outcome and implantrelated irritation after a mean followup of 39 months in the original cohort of the randomized controlled trial [21] comparing plate versus IM nail fixation for displaced midshaft clavicle fractures.

This study had numerous limitations. First, implant-related irritation is a subjective measurement as is the decision to remove an implant. By classifying the severity of the implant-related irritation and standardizing the questions, we tried to score irritation as consistent as possible. In the future we think this classification could be helpful by applying consistent indications to make a decision regarding implant removal. Second, a multicenter study in which multiple surgeons participate may lead to variable and possibly unpredictable results. However, surgical techniques, postoperative rehabilitation, followup, and indications for revision surgery were standardized to ensure uniformity regarding these issues across the participating hospitals. Third, one could question the accuracy of the answers conducted via telephone. However, verbally conducted QuickDASH scores replicate clinically relevant scores of the written QuickDASH and have good test-retest performance [12]. Fourth, the QuickDASH score is not specifically designed for patients with a displaced midshaft clavicle fracture. Nevertheless, it often is used as one of the tools to measure function [1, 4, 18-20]. Fifth, because patients experience and recall symptoms differently, we know this study could be susceptible to recall bias. By asking patients the same (standardized) questions and ensuring they were not aware of the study hypothesis, we think the recall bias is low. Finally, the standardized flowchart (Fig. 1) we used to classify the severity of the subjective implant-related irritation is not validated. By focusing on the subsequent actions the patient is willing to take, we believe it is useful to inform patients correctly regarding postoperative irritation or removal rates.

In contrast to results of van der Meijden et al. [21], who reported faster recovery during the first 6 months after plate fixation, no differences were observed in disability (QuickDASH scores) between plate and IM nail fixation after a mean followup of 39 months. Interpreting these 
Table 3. Postoperative complications beyond the first postoperative year

\begin{tabular}{|c|c|c|c|c|c|}
\hline Complications & Treatment & $\begin{array}{l}\text { Plate fixation } \\
(\mathrm{n}=56)^{\dagger} \text { Number }(\%)\end{array}$ & $\begin{array}{l}\text { IM fixation } \\
(\mathrm{n}=60)^{\ddagger} \text { Number }(\%)\end{array}$ & $\begin{array}{l}\text { Relative risk }(95 \% \\
\text { CI) }\end{array}$ & $\mathrm{p}$ Value \\
\hline Superficial infection & Antibiotics & 0 & 0 & - & - \\
\hline Deep infection & Surgical drainage & 0 & 0 & - & - \\
\hline $\begin{array}{l}\text { Implant-related } \\
\text { irritation }\end{array}$ & & & & & $<0.001 * *$ \\
\hline \multirow[t]{4}{*}{ Yes } & Observation & $18(32)$ & $5(8)$ & $3.86(1.5-9.7)$ & \\
\hline & Implant shortening ${ }^{\wedge}$ & 0 & $1(2)$ & $0.98(0.9-1.0)$ & \\
\hline & Implant removal, local anesthesia & 0 & $1(2)$ & $0.98(0.9-1.0)$ & \\
\hline & $\begin{array}{l}\text { Implant removal, general } \\
\text { anesthesia }\end{array}$ & $10(18)$ & $1(2)$ & $10.71(1.4-81.0)$ & \\
\hline No* & & $28(50)$ & $52(87)$ & $0.57(0.4-0.8)$ & \\
\hline Implant failure & Major revision & 0 & 0 & - & - \\
\hline Nonunion & Major revision & 0 & 0 & - & - \\
\hline $\begin{array}{l}\text { Refracture after } \\
\text { removal }\end{array}$ & Major revision & 0 & 0 & - & - \\
\hline Cold intolerance & & $10(18)$ & $10(17)$ & $1.05(0.5-2.4)$ & 0.865 \\
\hline
\end{tabular}

$\overline{\mathrm{IM}}=$ intramedullary; ${ }^{\dagger}$ two patients lost to followup; ${ }^{\star}$ two patients died, and are not included for analysis; $* *$ significant with $\mathrm{p}<0.05 ;{ }^{\wedge}$ partial removal of the protruding end of the titanium elastic nail with patient under local anesthesia, only the broken tip was removed; *includes 16 plates and 45 nails removed before the 1-year followup moment.

disability scores, one may conclude plate fixation could be favorable for early rehabilitation protocols or return to sports. However, there was no difference between the two groups 39 months postoperatively.

Biomechanical studies also showed plate fixation provided a more rigid construct, especially in rotational stability, compared with IM nail fixation [5, 17]. As these biomechanical studies reported on time-0 testing, not taking biologic influences into account, we can relate only to the short-term predictions and these findings probably could not be used for advice regarding return to sports [5, 17].

In the current study, QuickDASH scores improved marginally after 1 year, and were comparable to previously reported data after long-term followup [10, 14, 16]. Results of one study indicated that shoulder disability scores reached a steady state 1 year postoperatively [19]. After 1 year, the improvement in shoulder disability scores of patients treated surgically was less than 10 and 8 points, which are the minimal numbers for a clinically important difference for the DASH and QuickDASH, respectively $[8,13,19]$.

Implant-related irritation is a troubling, subjective endpoint because symptoms likely are governed by a multitude of variables including patient pain perception, bone quality, thickness of the overlying soft tissue, and possibly the surgeon's experience. These patient- and surgeon-specific variables may explain the wide variation in irritation rates reported by others $(9 \%-64 \%)[1,4,6,20,22,23]$. Some surgeons consider irritation as discomfort coexisting with the treatment rather than a complication. For this reason, we did not aim to quantify irritation but rather focused on the actions needed to treat the irritation based on intensity per the patient's perspective.

Our study showed high implant-related irritation and removal rates, especially in the IM nail fixation group. This could be explained by the relatively high amount of wedge and complex fractures $(61 \%)$. We believe these fractures are prone to intra- or postoperative shortening of the clavicle causing the pin to migrate and irritate; IM nail fixation therefore is probably less suitable for these type of fractures.

Naimark et al. [14] reported patient-reported outcomes after plate fixation of midshaft clavicle fractures and also completed an implant-related outcome survey in 73 patients. They reported a substantially lower overall plate removal rate compared with the rate in our study $(15 \%$ versus $50 \%)$. The lower response rate they reported $(66 \%$ versus $97 \%$ ) could be an explanation for this. Patients doing poorly or pursuing implant removal elsewhere may be less likely to respond to the questionnaires. Another $12 \%$ of their patients expressed a strong desire to have the plate removed [14], which is comparable to the $11 \%$ in this study.

van der Meijden et al. [21] reported a total of three infections and six major complications, although none of these developed after the 1 year followup. An explanation for the low major complication rates, like implant failure, could be that in half of the patients (16 in the plate group and 45 in the IM nail group) the implant had been removed 
before the 1-year followup [21]. Only a few studies have analyzed complications with followup beyond the first year after surgical treatment of displaced midshaft clavicle fractures $[2,10,11,14]$. Comparable to the current study, they reported low rates of infection, failure, and nonunion. Therefore, it may be concluded that implant-related irritation is the most frequent complication and seems to be the most frequent reason that necessitated implant removal $[2,10,11,14]$.

At final followup implants were removed more often after IM nailing in our patients. However, after the first year of followup, more implant removals were done in the plate group compared with the IM nailing group. Although implant removal with patients receiving local anesthesia seems to be an advantage of IM nail fixation, several patients preferred general anesthesia owing to fear of the surgical procedure with local anesthesia. An explanation for the higher percentage of irritation and implant removal in the plate group between the 1-year and the final followup could be that a large proportion of the implants in the IM nail fixation group had been removed within the first year postoperatively. In other words a larger proportion of plates was still in situ after one year, which potentially could cause irritation.

After a mean followup of 39 months, shoulder function was excellent and only marginally improved after 1 year for patients with plate and IM nail fixation of displaced midshaft clavicle fractures. Major complications did not occur after the 1-year followup. A frequent and bothersome problem after both surgical treatments is implant-related irritation, resulting in high rates of implant removal, and also after a period of one year. Clinical followup therefore should be extended beyond the first postoperative year. Future research could focus on using standardized questions to classify the severity of the subjective implantrelated irritation. Analyzing risk factors, like fracture classification, for implant irritation or removal could be another subject to focus on in the search for the optimal implant choice.

Acknowledgments We thank R. Lokerman BSc (School of Medicine, Utrecht University, Utrecht, The Netherlands) for help completing the telephone survey and J. Gruber BA (School of Medicine and Dentistry, University of Rochester Medical Center, Rochester, NY, USA) for help in editing the manuscript. We also thank Olivier van der Meijden MD, PhD and Frans-Jasper Wijdicks MD, PhD (both from the Department of Surgery, Diakonessenhuis Utrecht, Utrecht, The Netherlands) for their outstanding work in the previously conducted multicenter randomized controlled trial.

\section{References}

1. Andrade-Silva FB, Kojima KE, Joeris A, Santos Silva J, Mattar R Jr. Single, superiorly placed reconstruction plate compared with flexible intramedullary nailing for midshaft clavicular fractures: a prospective, randomized controlled trial. J Bone Joint Surg Am. 2015;97:620-626.

2. Ashman BD, Slobogean GP, Stone TB, Viskontas DG, Moola FO, Perey BH, Boyer DS, McCormack RG. Reoperation following open reduction and plate fixation of displaced mid-shaft clavicle fractures. Injury. 2014;45:1549-1553.

3. Beaton DE, Wright JG, Katz JN; Upper Extremity Collaborative Group. Development of the QuickDASH: comparison of three item-reduction approaches. J Bone Joint Surg Am. 2005;87:10381046.

4. Canadian Orthopaedic Trauma Society. Nonoperative treatment compared with plate fixation of displaced midshaft clavicular fractures: a multicenter, randomized clinical trial. J Bone Joint Surg Am. 2007;89:1-10.

5. Drosdowech DS, Manwell SE, Ferreira LM, Goel DP, Faber KJ, Johnson JA. Biomechanical analysis of fixation of middle third fractures of the clavicle. J Orthop Trauma. 2011;25:39-43.

6. Frigg A, Rillmann P, Ryf C, Glaab R, Reissner L. Can complications of titanium elastic nailing with end cap for clavicular fractures be reduced? Clin Orthop Relat Res. 2011;469:3356-3363.

7. George DM, McKay BP, Jaarsma RL. The long-term outcome of displaced mid-third clavicle fractures on scapular and shoulder function: variations between immediate surgery, delayed surgery, and nonsurgical management. $J$ Shoulder Elbow Surg. 2015;24:669-676.

8. Gummesson C, Atroshi I, Ekdahl C. The disabilities of the arm, shoulder and hand (DASH) outcome questionnaire: longitudinal construct validity and measuring self-rated health change after surgery. BMC Musculoskelet Disord. 2003;4:11.

9. Gummesson C, Ward MM, Atroshi I. The shortened disabilities of the arm, shoulder and hand questionnaire (QuickDASH): validity and reliability based on responses within the full-length DASH. BMC Musculoskelet Disord. 2006;7:44.

10. Lechler P, Sturm S, Boese CK, Bockmann B, Schwarting T, Ruchholtz S, Lahner M, Frink M. Surgical complications following ESIN for clavicular mid-shaft fractures do not limit functional or patient-perceived outcome. Injury. 2016;47:899903.

11. Leroux T, Wasserstein D, Henry P, Khoshbin A, Dwyer T, Oqilvie-Harris D, Mahomed N, Veillette C. Rate of and risk factors for reoperations after open reduction and internal fixation of midshaft clavicle fractures: a population-based study in Ontario, Canada. J Bone Joint Surg Am. 2014;96:1119-1125.

12. London DA, Stepan JG, Boyer MI, Calfee RP. Performance characteristics of the verbal QuickDASH. J Hand Surg Am. 2014;39:100-107.

13. Mintken PE, Glynn P, Cleland JA. Psychometric properties of the shortened disabilities of the arm, shoulder, and hand questionnaire (QuickDASH) and numeric pain rating scale in patients with shoulder pain. J Shoulder Elbow Surg. 2009;18:920-926.

14. Naimark M, Dufka FL, Han R, Sing DC, Toogood P, Ma CB, Zhang AL, Feeley BT. Plate fixation of midshaft clavicular fractures: patient-reported outcomes and hardware-related complications. J Shoulder Elbow Surg. 2016;25:739-746.

15. Nowak J, Holgersson M, Larsson S. Can we predict long-term sequelae after fractures of the clavicle based on initial findings? A prospective study with nine to ten years of follow-up. J Shoulder Elbow Surg. 2004;13:479-486.

16. Ranalletta M, Rossi LA, Bongiovanni SL, Tanoira I, Piuzzi NS, Maignon G. Surgical treatment of displaced midshaft clavicular fractures with precontoured plates. J Shoulder Elbow Surg. 2015;24:1036-1040.

17. Renfree T, Conrad B, Wright T. Biomechanical comparison of contemporary clavicle fixation devices. J Hand Surg Am. 2010;35:639-644. 
18. Robinson CM, Goudie EB, Murray IR, Jenkins PJ, Ahktar MA, Read EO, Foster CJ, Clark K, Brooksbank AJ, Arthur A, Crowther MA, Packham I, Chesser TJ. Open reduction and plate fixation versus nonoperative treatment for displaced midshaft clavicular fractures: a multicenter, randomized, controlled trial. $J$ Bone Joint Surg Am. 2013;95:1576-1584.

19. Schemitsch LA, Schemitsch EH, Veillette C, Zdero R, McKee MD. Function plateaus by one year in patients with surgically treated displaced midshaft clavicle fractures. Clin Orthop Relat Res. 2011;469:3351-3355.

20. Smekal V, Irenberger A, Struve P, Wambacher M, Krappinger D, Kralinger FS. Elastic stable intramedullary nailing versus nonoperative treatment of displaced midshaft clavicular fractures: a randomized, controlled, clinical trial. J Orthop Trauma. 2009;23:106-112.
21. van der Meijden OA, Houwert RM, Hulsmans M, Wijdicks FJ, Dijkgraaf MG, Meylaerts SA, Hammacher ER, Verhofstad MH, Verleisdonk EJ. Operative treatment of dislocated midshaft clavicular fractures: plate or intramedullary nail fixation? A randomized controlled trial. J Bone Joint Surg Am. 2015;97:613-619.

22. Wijdicks FJ, Houwert M, Dijkgraaf M, de Lange D, Oosterhuis K, Clevers G, Verleisdonk EJ. Complications after plate fixation and elastic stable intramedullary nailing of dislocated midshaft clavicle fractures: a retrospective comparison. Int Orthop. 2012;36:2139-2145.

23. Zhu Y, Tian Y, Dong T, Chen W, Zhang F, Zhang Y. Management of the mid-shaft clavicle fractures using plate fixation versus intramedullary fixation: an updated meta-analysis. Int Orthop. 2015;39:319-328. 